\title{
Isolation of Chlamydia trachomatis from Bartholin's ducts
}

\author{
JEAN A. DAVIES, ElisABETH REES, D. HOBSON, AND P. KARAYIANNIS \\ From the Liverpool Royal Infirmary and the Department of Medical Microbiology, \\ University of Liverpool, Liverpool
}

SUMMARY Exudate from Bartholin's ducts from 30 selected patients was investigated for Chlamydia trachomatis and Neisseria gonorrhoeae. $N$. gonorrhoeae was isolated from the duct exudate in 24 patients and $C$. trachomatis in nine. Concurrent infection of the ducts was present in seven $(29 \cdot 2 \%)$; the remaining two patients were sexual contacts of men with non-specific urethritis. The duct exudate was mucopus in seven patients, cloudy mucus in one, and clear mucus in the other. Although contamination of the vulva by $C$. trachomatis derived from cervical or urethral infection cannot be excluded, three cases are described which suggest that a true infection of the duct occurs and may persist after gonococcal infection has been cured.

\section{Introduction}

It has been known for 240 years (Astruc, 1737) that inflammation of Bartholin's ducts can be one manifestation of sexually transmitted disease. Rees (1967) found that Neisseria gonorrhoeae could be isolated from the exudate expressed from Bartholin's ducts in $52(28.4 \%)$ of 183 consecutive cases of gonorrhoea. The exudate obtained was classified as mucous or mucopurulent in only $58.4 \%$ of cases. Contamination from the labia cannot be excluded, but in five cases the ducts were the only site from which an isolate was obtained. In these five cases mucopus was expressed from the duct in two and clear mucus in two; in the remaining case no exudate was obtained and the culture plate was inoculated with a lacrymal probe specimen. Thus in gonococcal infection of Bartholin's ducts the same range of clinical signs is found as in other sites.

It is now apparent that genital infections with Chlamydia trachomatis are common in clinics for sexually transmitted disease. Intracellular inclusions in scrapings from the genital tract of the adult and from the conjunctiva of the newborn-similar to those found in trachoma-were reported as early as 1909 (Halberstaedter and Von Prowazek, 1909; Lindner, 1910), but final confirmation that these were the causative, infectious agents awaited the

Address for reprints: Dr J. A. Davies, Department of Venereology, Liverpool Royal Infirmary, Pembroke Place, Liverpool L3 5PU

Received for publication 18 May 1978 development of isolation techniques, initially in chick embryo and later in tissue culture. $C$. trachomatis was isolated from the cervix in 1959 (Jones et al, 1959), from the rectum in 1969 (Dunlop et al, 1969), and from the female urethra in 1972 (Dunlop et al, 1972). Isolation of $C$. trachomatis directly from Bartholin's duct exudate has not yet been reported. This paper reports an investigation of 30 women in whom Bartholin's duct exudate was examined for both $C$. trachomatis and $N$. gonorrhoeae.

\section{Materials and methods}

\section{CLINICAL EXAMINATION}

These 30 women form a selected series, in which the majority were cases of gonorrhoea. Swabs for $N$. gonorrhoeae were taken from the urethra, Bartholin's ducts or exudate, endocervix, and rectum and inoculated on to a selective medium containing antibiotics (London Analytical and Bacteriological Media Ltd.) before smears for Gram-staining were prepared. A diagnosis of gonorrhoea was made when $N$. gonorrhoeae was present in any site by culture or when intracellular Gram-negative diplococci were present on Gramstained smear or both. The exudate from Bartholin's duct was obtained, after the labium had been wiped with a sterile swab, by introducing a finger into the vagina and massaging the length of the duct. Specimens were obtained with cottonwool-tipped swabs in all except two patients. In these two patients no exudate was obtained by massage, and a lacrymal probe was used to obtain material from 
the ducts. Endocervical swabs were taken after a Cusco's vaginal speculum had been inserted into the vagina and all the vaginal discharge had been removed. The cervix was wiped with a sterile cottonwool swab, and a cottonwool-tipped swab was inserted into the cervical canal and rotated firmly round the mucosa. The swab for chlamydial culture also was rubbed on any ectopic, columnar epithelium present. The first specimen obtained in all cases was used for gonococcal investigation and the second specimen for isolation of Chlamydia.

\section{LABORATORY EXAMINATION}

Swabs for $C$. trachomatis were immediately immersed in $3.0 \mathrm{ml}$ of transport medium in screwtopped bottles and stored at $4^{\circ} \mathrm{C}$ until inoculated on to tissue culture media, which usually took place between two and four hours later but occasionally after $\mathbf{2 4}$ hours. The swab contents were thoroughly dispersed into the transport medium and $0.2 \mathrm{ml}$ of the mixture was then inoculated on to each of two McCoy cell coverslip cultures (MCC). Most steps in the laboratory procedure were as described previously (Johnson and Hobson, 1976; Johnson et al, 1978).

McCoy cell cultures were prepared by low speed centrifugation of $1.5 \times 10^{5}$ McCoy cells in $1.0 \mathrm{ml}$ growth medium on $10 \mathrm{~mm}$ coverslips contained in a $5 \mathrm{ml}$ screw-topped bottle. After the McCoy cell cultures had been incubated for 24 hours at $37^{\circ} \mathrm{C}$ and immediately before inoculation of the specimens $0.1 \mathrm{ml}$ of an aqueous solution of cycloheximide (BDH) was added to each culture to give a final concentration of $1.0 \mu \mathrm{g} / \mathrm{ml}$. The purpose of this additive was to slow down but not prevent further McCoy cell replication. Inoculated McCoy cell cultures were incubated for a further 48 hours at $37^{\circ} \mathrm{C}$; the coverslips were then fixed, Giemsastained, and examined by darkground microscopy. The number of chlamydial inclusions per coverslip was counted on each coverslip. The isolation rate of chlamydiae from cervical swabs was only slightly higher by the new method than by the previous one, but the former method has been adopted because it was simpler in practice.

All patients were investigated for syphilis, trichomoniasis, and candidosis by conventional methods.

\section{RECORDING OF CLINICAL SIGNS}

Clinical signs were recorded at the time the specimens were taken. The Bartholin's duct exudate was described as mucopurulent when yellow (Fig. 1a, b), as mucoid when white, as cloudy mucus when it consisted basically of mucus with faint streaks of white, which made the exudate slightly opaque (Fig. 2), and as clear mucus (Fig. 3).

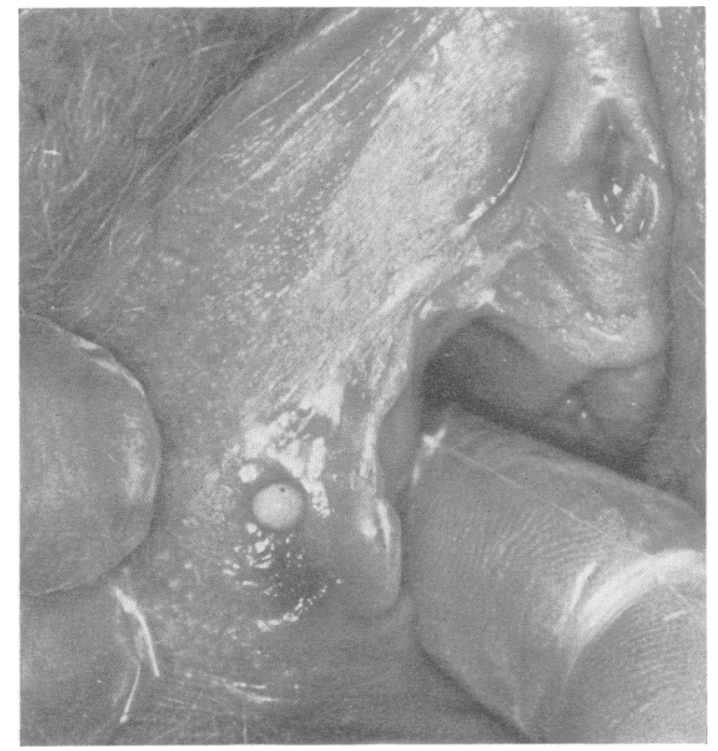

Fig. 1a Bead of mucopus expressed from right Bartholin's duct

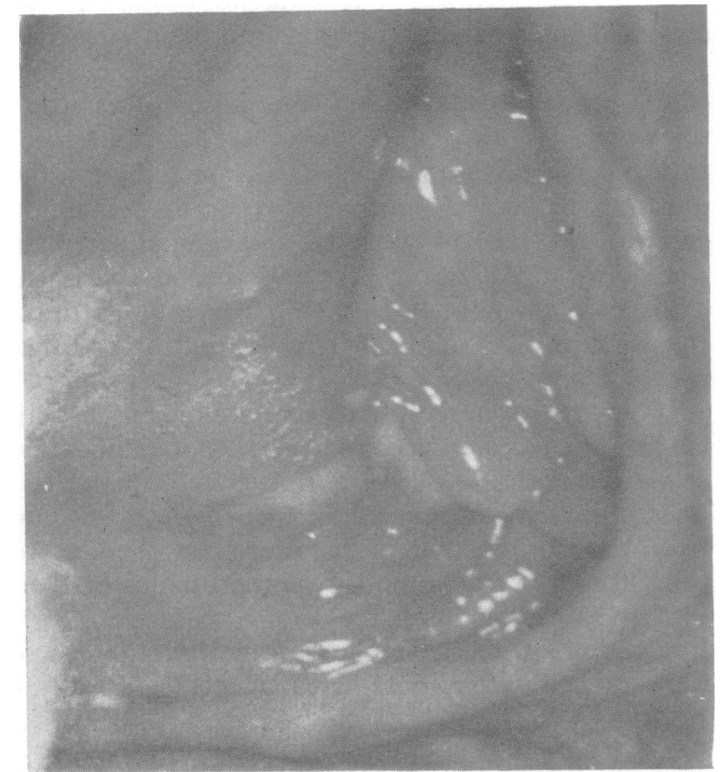

Fig. 1b Mucopus expressed from four separate ducts of right Bartholin's gland 


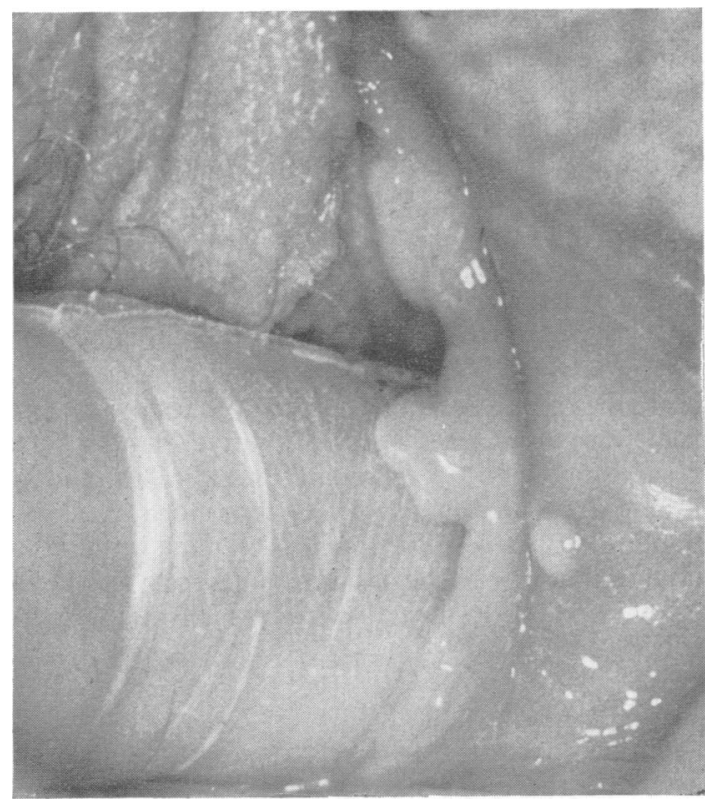

Fig. 2 Bead of cloudy mucus expressed from left Bartholin's duct

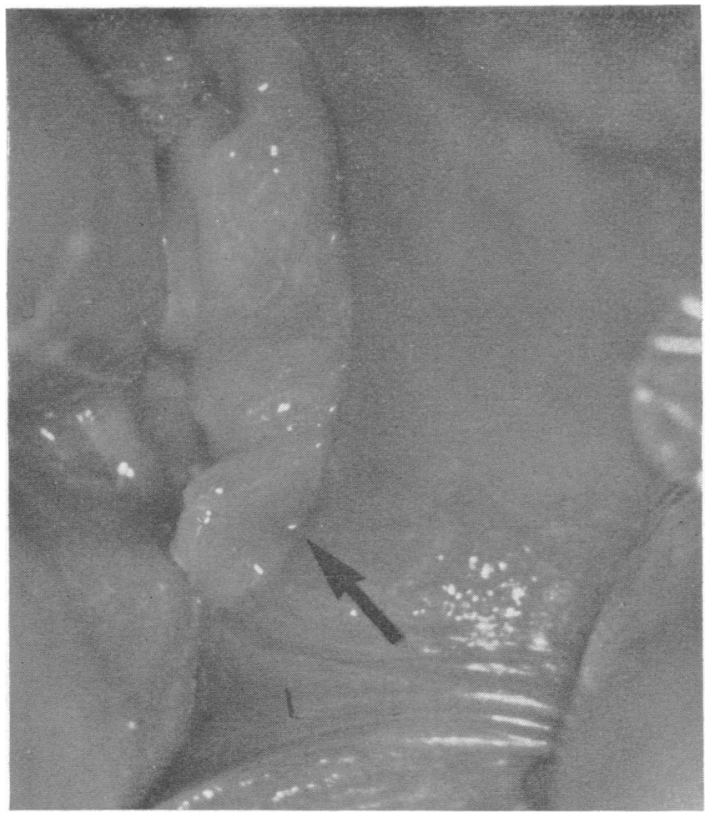

Fig. 3 Clear mucus expressed from left Bartholin's duct

\section{Results}

$N$. gonorrhoeae was isolated from one or a combination of sites in 24 patients, and $C$. trachomatis from 16. Concurrent infection was present in $14(53 \%)$ patients (Table 1). This incidence of concurrent infection is similar to that found from cervical swabs in a series of consecutive patients with gonorrhoea who were examined previously in this unit; $C$. trachomatis was isolated in $111(52.9 \%)$ of 210 women investigated (Davies et al, unpublished report).

$N$. gonorrhoeae was isolated from Bartholin's duct exudate in 24 patients and $C$. trachomatis in nine; concurrent infection of the ducts was present in seven $(29 \cdot 2 \%)$ (Table 1$)$.

Table 1 Isolation of Neisseria gonorrhoeae and Chlamydia trachomatis

\begin{tabular}{lll}
\hline & \multicolumn{1}{c}{ No. of patients with specimens from } \\
\cline { 2 - 3 } Laboratory results & Any site & Bartholin's ducts \\
\hline $\begin{array}{l}\text { N. gonorrhoeae-positive } \\
\text { and }\end{array}$ & \\
$\quad \begin{array}{l}\text { Chlamydia-positive } \\
\quad \text { Chlamydia-negative }\end{array}$ & 14 & 7 \\
$\begin{array}{l}\text { Nonorrhoeae-negative } \\
\text { and }\end{array}$ & 10 \\
$\quad$ Chlamydia-positive & 2 & 17 \\
$\quad$ Chlamydia-negative & 4 & 2 \\
\hline
\end{tabular}

C. trachomatis was isolated from Bartholin's ducts in two patients from whom gonococci were not isolated. These patients were sexual contacts of men with non-specific urethritis, and the exudate from the duct was cloudy in one patient and clear mucus in the other. In the seven patients with concurrent infection of the duct the exudate was mucopurulent.

The type of exudate expressed in the 21 Chlamydianegative patients is shown in Table 2 .

In five of the 17 gonococci-positive, Chlamydianegative patients the exudate was normal, that is, clear or cloudy mucus. This is similar to the findings of Rees (1967).

Table 2 Type of exudate from Bartholin's duct in 21 patients with negative results to Chlamydia isolation

\begin{tabular}{lllll}
\hline & \multicolumn{2}{c}{ Type of exudate from } & Chlamydia-negative patients \\
\cline { 2 - 5 } & $\begin{array}{l}\text { Muco- } \\
\text { purulent }\end{array}$ & Mucoid & $\begin{array}{l}\text { Cloudy } \\
\text { mucus }\end{array}$ & $\begin{array}{l}\text { Clear } \\
\text { mucus }\end{array}$ \\
\hline Laboratory findings & & & & \\
\hline $\begin{array}{l}\text { N. gonorrhoeae } \\
\text { isolation } \\
\begin{array}{l}\text { Positive } \\
\text { Negative }\end{array}\end{array}$ & 11 & 1 & 3 & 2 \\
\hline
\end{tabular}




\section{CASE HISTORIES}

Although the vulva was cleaned with a dry swab before the duct was massaged, it is not possible to exclude contamination of the vulval mucosa, and hence of the specimen, by chlamydiae derived from cervical or urethral infection. The following three case histories, however, suggest that true infection of the duct can occur.

\section{Case 1}

An 18-year-old, single, English patient attended as a sexual contact of a man with gonorrhoea; she complained of vaginal discharge and vulvo-vaginal irritation. The clinical and microbiological findings are shown in Table 3.

Clinical signs of infection were found at all sites except the rectum. Both $N$. gonorrhoeae and $C$. trachomatis were isolated from all sites. An additional swab for Chlamydia was taken from the vulva on completion of the examination-that is, after the exudate in the urethra and Bartholin's ducts had been expressed-by rubbing a swab on the mucosal surface of the labia minora and the fourchette. The highest inclusion counts were found in the Bartholin's duct exudate. This suggests active infection of the ducts rather than contamination of the vaginal orifice. The lower vulval count suggests that the vulva was contaminated by organisms from the Bartholin's duct exudate rather than the reverse.
Case 2

An 18-year-old, single, English patient presented on the 15 February 1977 of her own accord complaining of pubic lice and vulvo-vaginal irritation. The clinical and microbiological findings are recorded in Table 4.

The diagnosis of gonorrhoea was made solely on positive results from the Gram-stained smear from the right Bartholin's duct, all culture results being given as negative. The patient was treated with procaine penicillin 1.2 megaunits intramuscularly and ampicillin $1 \mathrm{~g}$ orally, and all the follow-up tests for $N$. gonorrhoeae gave negative results. The reisolation of $C$. trachomatis from Bartholin's duct after treatment for gonorrhoea indicated continuing active infection of the duct rather than contamination of the labium, since cervical swabs gave persistently negative results throughout the follow-up period.

\section{Case 3}

The third patient, a 16-year-old, single, English girl, attended the clinic as a sexual contact of a man with gonorrhoea. She was asymptomatic. The clinical and microbiological findings are recorded in Table 5.

Clinical signs of infection were found in both Bartholin's ducts. N. gonorrhoeae was isolated from the urethra, cervix, and right Bartholin's duct. C. trachomatis was isolated from the right Bartho-

Table 3 Clinical and microbiological findings (Case 1)

\begin{tabular}{|c|c|c|c|c|c|c|}
\hline \multirow[b]{2}{*}{ Findings } & \multirow[b]{2}{*}{ Urethra } & \multicolumn{2}{|c|}{ Bartholin's duct } & \multirow[b]{2}{*}{ Cervix } & \multirow[b]{2}{*}{ Rectum } & \multirow[b]{2}{*}{ Labia } \\
\hline & & Right & Left & & & \\
\hline $\begin{array}{l}\text { Type of exudate } \\
N \text {. gonorrhoeae }\end{array}$ & Mucopus & Mucopus & Mucopus & Mucopus & None & \\
\hline $\begin{array}{l}\text { isolation } \\
\text { Chlamydia }\end{array}$ & + & + & + & + & + & NT \\
\hline isolation * & 26 & 76 & 121 & 3 & 2 & 5 \\
\hline
\end{tabular}

Table 4 Clinical and microbiological findings on first visit and after treatment (Case 2)

\begin{tabular}{|c|c|c|c|c|c|c|c|c|}
\hline \multirow[b]{3}{*}{ Findings } & \multicolumn{8}{|c|}{ Site of infection and examination at } \\
\hline & \multicolumn{2}{|l|}{ Initial visit } & \multicolumn{2}{|c|}{ Eight days } & \multicolumn{2}{|l|}{15 days } & \multicolumn{2}{|l|}{ Six weeks } \\
\hline & $R B D$ & Cervix & $R B D$ & Cervix & $R B D$ & Cervix & $R B D$ & Cervix \\
\hline $\begin{array}{l}\text { Type of exudate } \\
N \text {. gonorrhoeae }\end{array}$ & Mucopus & Clear mucus & None & Clear mucus & Clear mucus & Clear mucus & Clear mucus & Clear mucus \\
\hline $\begin{array}{l}\text { isolation } \\
\text { Chlamydia }\end{array}$ & + & - & - & - & - & - & - & - \\
\hline isolation* & 2 & 142 & - & - & 52 & - & 4 & - \\
\hline
\end{tabular}

+ Positive - negative

*Inclusion forming units per whole coverslip

RBD = Right Bartholin's duct 
Table 5 Clinical and microbiological findings on first visit and after treatment (Case 3)

\begin{tabular}{|c|c|c|c|c|c|c|c|c|}
\hline \multirow[b]{3}{*}{ Findings } & \multicolumn{8}{|c|}{ Site of infection and examination at } \\
\hline & \multicolumn{2}{|c|}{ Initial visit } & \multicolumn{2}{|c|}{ One week } & \multicolumn{2}{|l|}{ Two weeks } & \multicolumn{2}{|c|}{ Three weeks } \\
\hline & $R B D$ & Cervix & $R B D$ & Cervix & $R B D$ & Cervix & $R B D$ & Cervix \\
\hline Type of exudate & Mucopus & $\begin{array}{l}\text { Cloudy } \\
\text { mucus }\end{array}$ & None & Clear mucus & Clear mucus & Clear mucus & $\mathbf{L P}$ & Clear mucus \\
\hline $\begin{array}{l}N . \text { gonorrhoeae } \\
\text { isolation } \\
\text { Chlamydia }\end{array}$ & + & + & - & - & 一 & - & - & - \\
\hline isolation $*$ & 12 & 2789 & - & - & 23 & 11 & 67 & 21 \\
\hline
\end{tabular}

+ Positive - negative

*Inclusion forming units per whole coverslip

RBD = Right Bartholin's duct

$\mathbf{L P}=$ Lacrymal probe specimen

lin's duct and the cervix, but swabs from the urethra, left Bartholin's duct, and the vulva gave negative results.

The patient was treated with procaine penicillin 1.2 megaunits intramuscularly and amoxycillin 500 mg orally; all follow-up tests for gonorrhoea gave negative results. $C$. trachomatis was reisolated from the right Bartholin's duct and the cervix two and three weeks after penicillin treatment. On both occasions the inclusion count was higher in the duct exudate than in the swab taken from the cervix.

\section{Discussion}

The exudate from Bartholin's ducts in 30 selected patients examined at a clinic for STDs was investigated for $N$. gonorrhoeae and $C$. trachomatis. Isolates of $C$. trachomatis were obtained from nine patients, seven of whom had concurrent gonococcal infection. Although contamination of specimens by Chlamydia from other sites might be postulated, the highest inclusion count was obtained from the Bartholin's duct in one patient; persistence of C. trachomatis only in the duct occurred in another patient; and higher inclusion counts were obtained from the duct than from the cervix after treatment for gonorrhoea in a third patient.

From both cervical and Bartholin's duct specimens the same amount of homogenised swab material was centrifuged on the McCoy cells and inclusions were counted on the whole coverslip. Thus counts from the small amount of exudate obtained from Bartholin's ducts probably signify a much heavier infection of that small area of columnar epithelium than a similar count obtained from the far greater area of columnar epithelium of the endocervix, which is readily accessible for swabbing. These findings suggest that a true chlamydial infection of Bartholin's ducts occurs and that this site should be examined in women who are sexual contacts of men with chlamydial infection as it is in sexual contacts of men with gonorrhoea.

This work was supported by a project grant from the Medical Research Council.

We are indebted to Dr A. Percival for the microbiological investigations, to Dr G. C. Turner for serological tests for syphilis, and to the nursing staff for their invaluable assistance both with patients and in ensuring the rapid transfer of specimens to the laboratories.

\section{References}

Astruc, J. (1737). A Treatise of the Venereal Diseases, p.16, volume 2. Translated by W. Barrowby: London.

Dunlop, E. M. C., Hare, M. J., Darougar, S., Jones, B. R., and Rice, N. S. C. (1969). Detection of chlamydia (Bedsonia) in certain infections in man. Clinical study of genital tract, eye, rectum and other sites of recovery of Chlamydia. Journal of Infectious Diseases, $120,4,463-470$.

Dunlop, E. M. C., Darougar, S., Hare, M. J., Treharne, J. D., and Dwyer, R. St. C. (1972). Isolation of Chlamydia from the urethra of a woman. British Medical Journal, 1, 386.

Halberstaedter, L., and von Prowazek, S. (1909). Berliner klinische Wochenschrift, 46, 1839.

Johnson, F. W. A., and Hobson, D. (1976). Factors affecting the sensitivity of replicating McCoy cells in the isolation and growth of Chlamydia A. Journal of Hygiene, 76, 441-451.

Johnson, F. W. A., Chancerell, L. Y. J., and Hobson, D. (1978). An improved method for demonstrating the growth of chlamydiae in tissue culture. Medical Laboratory Sciences, 35, 67-74.

Jones, B. R., Collier, L. H., and Smith, C. H. (1959). Isolation of virus from inclusion blenorrhoea. Lancet, 1, 902-905.

Lindner, K. (1910). Zur aetiologie dei gonokokkenfrien urethritis. Weiner klinische Wochenschrift, 23, 283-284.

Rees, E. (1967). Gonococcal bartholinitis. British Journal of Venereal Diseases, 43, 150-156. 